\title{
Designing Menstrual Technologies with Adolescents
}

\author{
Marie Louise Juul Søndergaard \\ mljso@kth.se \\ KTH Royal Institute of Technology \\ Stockholm, Sweden
}

\author{
Marianela Ciolfi Felice \\ ciolfi@kth.se
}

KTH Royal Institute of Technology Stockholm, Sweden

\author{
Madeline Balaam \\ balaam@kth.se \\ KTH Royal Institute of Technology \\ Stockholm, Sweden
}
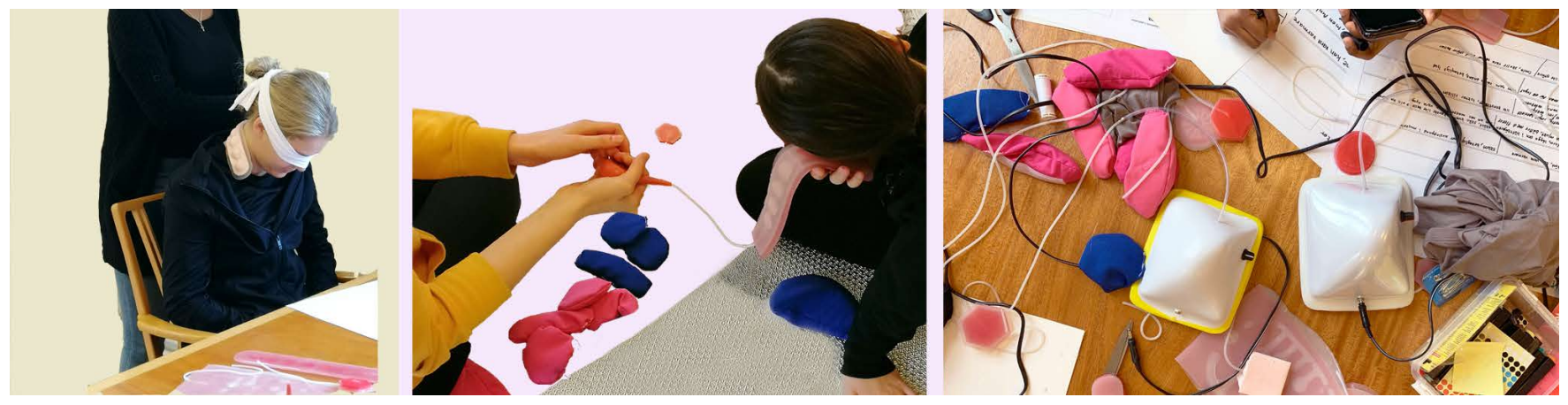

Figure 1: The toolkit Menarche Bits supports embodied ideation of interaction design for menstrual experiences.

\begin{abstract}
Starting to menstruate can restrict adolescents' movements due to physiological changes and societal stigma. We present a participatory soma design project advocating for young adolescents to listen to and care for their newly-menstruating bodies, specifically focusing on participation in sport. We designed Menarche Bits, an open-ended prototyping toolkit consisting of shape-changing actuators and heat pads, and used it in two design workshops with seven participants aged 16-18, as part of collaboration and menstrual advocacy in their sports clubs and high school. The participants designed menstrual technologies that respond to menstrual cramps and depressive, anxious feelings before menstruating. We contribute findings on designing menstrual technologies with adolescents using participatory soma design. We found that a toolkit approach to the design of menstrual technologies can allow for pluralist experiences of menstrual cycles. In addition, we found that participatory design with adolescents benefits from drawing on qualities of embodiment and participants' own body literacy.
\end{abstract}

\section{CCS CONCEPTS}

- Human-centered computing $\rightarrow$ Interaction design; Interaction design process and methods; Participatory design.

\section{KEYWORDS}

Menstrual Health, Soma Design, Feminist HCI, Participatory Design, Shape-changing Technologies

Permission to make digital or hard copies of part or all of this work for personal or classroom use is granted without fee provided that copies are not made or distributed for profit or commercial advantage and that copies bear this notice and the full citation on the first page. Copyrights for third-party components of this work must be honored

For all other uses, contact the owner/author(s).

CHI '21, May 8-13, 2021, Yokohama, Japan

(C) 2021 Copyright held by the owner/author(s)

ACM ISBN 978-1-4503-8096-6/21/05.

https://doi.org/10.1145/3411764.3445471
ACM Reference Format:

Marie Louise Juul Søndergaard, Marianela Ciolfi Felice, and Madeline Balaam. 2021. Designing Menstrual Technologies with Adolescents. In CHI Conference on Human Factors in Computing Systems (CHI '21), May 813, 2021, Yokohama, Japan. ACM, New York, NY, USA, 14 pages. https: //doi.org/10.1145/3411764.3445471

\section{INTRODUCTION}

Starting to menstruate can restrict adolescents' movements due to physiological changes and societal stigma, which in turn can lead adolescents to stay home from school or drop out of sports [42]. Having positive early menstrual experiences is crucial, since they can shape menstrual experiences later in life [40]. For adolescents it is not only important to learn about menstrual health "in theory", but also to surface and anchor knowledge in their own lived body, cultivate body awareness and a willingness to explore and feel comfortable in/with their menstruating bodies [62]. Technologies can be designed to produce knowledge and appreciation of the menstruating body through touching the body [13]; an interaction that implies coming into close contact with the body. However, how can designers and researchers involve adolescents who recently started to menstruate in design for menstrual health? And which technologies could be designed if young adolescents use their bodies and experiences as starting point for design?

We have carried out a participatory and soma-based research through design (RtD) project that advocates for making space for menarche in sport contexts. We follow a feminist agenda by approaching menarche and menstrual cycles as bodily-rooted yet socially experienced. Our research contributes with design work as menstrual advocacy that takes the menstruating body as a starting point; in particular the body as it moves and comes to know and act through movements. Starting to menstruate can decrease adolescents' participation in sport because of their bodily experiences and the social context of sports clubs or schools [42]. We wish to 
make space for such experiences by directly involving menstruating adolescents in the design of menstrual technologies. Through a collaboration with a sport-focused high school in Sweden, we have facilitated two design workshops with 7 adolescents aged 1618. In the workshops, we used an open-ended prototyping toolkit "Menarche Bits" that we designed to be used with young people who menstruate [57]. We used this toolkit in the design of bodyworn shape-changing technologies that respond to the participants' experiences of menarche and menstrual cycles in sport.

In this paper, we present and reflect on the workshops and the participants' design concepts; including shape-changing technologies for menstrual cramps, bloated stomach and pre-menstrual changes in mood. We contribute knowledge on how a toolkit approach to the design of menstrual technologies can allow for pluralist experiences of menstrual cycles. Secondly, we contribute with knowledge on how to do participatory design with adolescents in the topic of menstrual health, by drawing on the body and first-person experiences, and not only theory or education about menstrual cycles. Lastly, we contribute with design research and methods on engaging with menstrual cycles as a somatic and social experience, where the body and menstrual movements become inspiration for design. Our contribution towards designing menstrual technologies focuses on making space for the newlymenstruating body; technologies that both create comfort, enable free movement, and stimulate body literacy anchored in young menstruators' own lived body. We show and unpack that a somatic and social approach to menstrual cycles can help participants in research projects develop bodily awareness and to further notice their bodies, and remember, perhaps even re-embody, their past experiences. With a starting point in menstrual cycles, we offer a methodological contribution to HCI to develop deep bodily sensitivities in participatory research on bodily phenomena. Such a contribution can go beyond menstrual cycles to also include other bodily phenomena that are widely occurring, varied in experience, possibly tabooed, and may be difficult to recall at the time of research. We argue and demonstrate that developing such sensitivity is crucial in design workshops to deeply engage lived experience and inspire the design of radically different technologies that break with current norms and dominant design narratives.

\section{RELATED WORK}

Menarche is the first menstrual bleeding, typically occurring between the ages of 9-14. The first years of menstruation are key for positive menstrual experiences throughout life [47]. If adolescents feel ashamed of their body at menarche, it is possible that their shame and negative feelings about their body could remain for years [40]. Menarche marks the onset of menstrual cycles. The menstrual cycle starts with the first day of bleeding and ends the day before the bleeding returns. The menstrual cycle can be divided into phases: the menstrual, follicular, ovulation and luteal phase. The cycle can come with changes in bodily experience including changes in mood, menstrual cramps, tender breasts, bloated stomach, tiredness and headaches [16]. Each of these experiences varies from person to person, and cycle to cycle. Through adolescence, menstrual cycles can be long and irregular, making it more difficult to notice and understand changes in the body.
Historically, in patriarchal societies, menstruation has been stigmatized and tabooed, considered impure and dirty [38], and understood as a function of the female body affecting girls and women [26]. Menstruation has constructed women as an Other to a male norm, and placed menstruation as a marker of womanhood, e.g., manifested in the feminisation of menstrual hygiene products and gender-segregated bathrooms. This has led to the marginalisation of women and further perpetuated the gender binary. The gendering of menstruation as a biological marker of womanhood contributes to silencing and violating experiences of trans men, intersex and non-binary folks who experience monthly bleedings [20]. The prevailing gendered norms of concealing and controlling menstruation and hiding it from a public view [69] have further discriminated and marginalised women and girls with disabilities, who are socially constructed as unable to manage their own menstruation [54]. The forms of discrimination of people who menstruate are intersectional, and for the politically-engaged menstrual movement [64] to improve menstrual health for all, such plural and embodied experiences must drive the change.

\subsection{Menstrual Cycles in Sport}

Sport is a particular domain in which menstruating bodies have been overlooked [70]. Sport is a social phenomena where dominant patriarchal structures can be reproduced, e.g., when women athletes being rough, loud, and dirty "fail in femininity" [46]. Menstruation intensifies this discrimination. Young adolescents "accommodate and even suppress their menstruating bodies to the routines and requirements of sports" [42]. While socially evident, medical and sport research is still lacking knowledge on how menstrual cycles influence sport and exercise [11]. Only recently research has shown how menstrual cycles can influence body performance and thus suggesting how training can be adapted to the changes of the menstruating body [65]. Examples include the use of exercise to relieve menstrual cramps [37], the increased risk of knee injuries during the follicular phase [28], and the benefits of strength training during the first two weeks of the cycle [65].

While research is being conducted, key players in the sport industry is spreading awareness for menstrual cycles in sport. The first public relation between sports and menstruation came out in 2007 when United States American tennis player Serena Williams modelled in the tampon brand Tampax's "Mother Nature" campaign to empower menstruating adolescents and speak about "taboo topics like racism and women's bodies in sports" [48]. In 2015, musician and activist Kiran Gandhi ran the London marathon while freebleeding. In 2016, Chinese swimmer Fu Yuanhui broke the silence of menstruation in sport as she, during the Olympic games, told on live-TV that she was menstruating. In 2019, the United States women's soccer team won the world cup and made headlines about using menstrual tracking on the whole team; a strategy that has later been adopted by Chelsea Women's team. Also design and technologies has started putting new knowledge on menstrual cycles in sport into practice. FitrWoman is the name of the first menstrual tracking application that offers exercise programs tailored after the menstrual cycle, and menstrual hygiene product Libresse has also rolled out campaigns in Scandinavia to make menstrual cycles more visible in sports clubs. 
As the $\mathrm{HCI}$ community devotes more attention to the sports and exercise domain [43, 45], it is crucial to go beyond a nonmenstruating norm, and engage with sport from intersectional perspectives [41, 51, 63, 67].

\subsection{Menstruation in HCI and Design}

Menstrual research in $\mathrm{HCI}$ and Design has explored the design of technologies for menstrual health, and often followed a feminist [8] and women's health agenda [2]. Research has studied and analysed the use of existing menstrual cycle tracking applications [15] and menstrual products [44], and challenged their uses [30]. Design work has imagined how menstrual cycle technologies could be designed differently, e.g. generating and displaying information about the menstrual cycle in the home [17, 31], designing smart or digitally fabricated menstrual hygiene products $[39,56]$, and reimagining the public spaces (e.g. bathrooms) of menstruation $[19,61]$. Research have explored the sociotechnical implications of menstrual health education [62] and how it is delivered through digital platforms [60]. Redesign of menstrual health education has focused on design for children [58] and adolescents [35, 57], although individuals were only involved in evaluation and not the design work itself. Menstrual technologies have been critiqued for being gender-normative, and visual and written narratives have showed the violence this causes for trans and non-binary menstrual experiences [21, 53]; an example of how technologies can embody harmful essentialised articulations of embodiment and gender [36].

Across themes such as education, management, embodiment, and advocacy, related work points to the sociotechnical and political implications of menstrual technologies, and the continued need to reimagine how menstrual health education and care can be designed and delivered. Such work is increasingly moving towards "a care of menstruation" [6], engaging with the materiality and lived experiences of menstrual cycles, such as bodily fluids [13, 29], or menstrual pain [7]. This approach to menstrual technologies involves becoming comfortable with the materiality of the menstruating body, its pain and fluids, and moving from managing to caring for the body. Such an approach is in line with Tuli et al.'s implications for design of better menstrual health education for adolescents, which include "extending engagement" from learning about the body in theory to consider the quality of embodiment so that adolescents can "learn to engage with and feel comfortable in and with their bodies" [62].

\section{DESIGN WORKSHOPS WITH MENSTRUATING ADOLESCENTS}

In our research, we are inspired by a somaesthetic and feminist approach to menarche, which is expressed in our values and design process focusing on advocacy, embodiment, plurality and participation [8, 32, 33]. Soma design builds on somaesthetics as a "a way to examine and improve on all connections between sensation, feeling, emotion, and subjective understanding and values" and a way of increasing aesthetic appreciation through all senses [59]. The soma (body and mind) in movement is the starting point for soma design [34]. We advocate for a somaesthetic appreciation of menarche by listening to and caring for the changes of the newly-menstruating body [57], and by highlighting experiences of intimate touch [4]. We aim for creating social change through our collaboration with a high school, and by opening alliances with the participating adolescents who are enrolled in the school's sports program. Our approach is in line with Tuli et al.s implications for design of menstrual health education, which suggests to foster participation, engage stakeholders, promote safe spaces, and extend engagement to include embodied experiences and the cultivation of body-awareness [62].

As part of soma design, we involved our bodies and first-person experiences of menarche and menstrual cycles. The authors, who are between the ages of 29-38 and from Northern European and South American countries, all have experiences of menstruating, although not all authors menstruated during this project. During the design process, we recalled and re-enacted our menarche experiences to uncover the feelings and tensions that we experienced when starting to menstruate. We also increased our bodily awareness of our current bodies in sport activities. While it is not deemed necessary to menstruate to do research on menstrual health, our current and previous experiences of menstruating influenced our research process, both in terms of how we understand the subject of menstruation and how we relate to and empathize with the participants in our workshops. Inspired by participatory design [12], we invited adolescents who do sport and who recently started to menstruate to take part in two design workshops. As the first research project that involves adolescents into the design of menstrual technologies, we sought to establish new methods for creating a safe and comfortable space for participation. Drawing on research on children in design processes [9, 14, 52], we invited the participating adolescents to take the role as design partners in the research project, rather than merely users or testers of a technology. We used an open-ended prototyping kit called Menarche Bits [57], that we specially designed for menarche experiences, to drive and orchestrate the embodied ideation [66] process in the design workshops. We used the Menarche Bits toolkit because it aligned with our focus on somaesthetic awareness and offered a playful approach to designing for and with the body. Menarche Bits has not previously been tested nor explored together with their intended users (menstruating adolescents); thus we contribute with research on how Menarche Bits supports the exploration of menstrual experiences and prototyping of menstrual technologies.

\subsection{Recruitment}

Our recruitment focused on adolescents who started to menstruate and who did sport. We aimed to recruit broadly to engage a diverse group of participants, representing experiences of menstrual cycles beyond cisgender girls [53]. We reached out to a sport club, a national transgender youth community, a youth sexual and reproductive health community, and a high school. We went through established channels and enabled the adolescents to self-disclose if they started monthly bleedings. We received support from all channels, but only managed to recruit participants through the high school. The high school is located in Stockholm. It offers a national sport program which enables athletes to enroll in high school education while attending their daily training program. We recruited the participants through their teachers and sports coaches, who distributed our call on mailing lists and by directly addressing 
adolescents they knew had menstrual experiences that affected their sport (such as strong pre-menstrual mood changes lowering motivation for performing, or menstrual cramps that hindered participation). We had an initial meeting with the high school's dean and a separate meeting with the sport coaches to inform them about our research plan. After the initial meeting with the dean of the high school, we received written approval on email for organizing workshops with the students. The dean furthermore proposed and approved that participants could take part in the workshops instead of attending their normal sports schedule. We received interest from 11 adolescents who all were invited to an initial meeting, where they met the first author to get more information about the research goals and workshop activities, having the opportunity to ask questions. The adolescents received two exemplars of information sheets and informed consent (one for themselves and one for their parent(s)), and they were asked to go through the information sheet and sign with their parents, if they wished to participate. As the participants were minors, it was crucial to get their parents' consent, but we also wanted the participants' own consent to acknowledge their own agency. After the initial meeting, 10 adolescents signed up for the workshops, however since some got sick or could not participate without giving a reason, only seven joined the workshops.

3.1.1 Participants. The workshop participants were seven girls between the ages of 16-18. Their menarcheal ages were between 11-15 years, and they had been menstruating for 2-6 years. All participants were of Swedish nationality. They were participating in the following sports activities: volleyball (3), football (soccer) (3), and basketball (1). Cinema tickets were provided as gifts to the participants. The participants and their parents gave informed consent to participate in the research. All names have been anonymized for publication. The first workshop's participants were: Eva (volleyball), Ida (volleyball), Lena (basketball), and Wilma (volleyball). The second workshop's participants were: Ann (soccer), Astrid (soccer), and Elsa (soccer). The participants who played the same sports already knew each other, while the participants that did not play the same sports met for the first time in the workshop.

\subsection{Workshop Procedure}

We organised two four-hour workshops. Each workshop was with different participants and both followed the same procedure. The workshops were organised at the participants' high school in a private room only accessible by staff members. The workshop was mainly in the participants' native language. We brought yoga mats and design materials, and in the room we had access to a table and chairs. The school offered water and fruit, and we provided the girls' choice of toasted sandwiches. The workshop started with a short introduction by the first author on menstrual cycles, its distinct phases, and on sports, including popular news stories from the sport world about menstrual cycles. The first author presented the workshop schedule and emphasised that the workshop would take as a starting point their own experiences, rather than textbook knowledge about menstrual cycles. Then she invited the participants to make rules for the workshop, with the aim of allowing participants' to take ownership over workshop.
3.2.1 Drawing Menstrual Cycles. The workshop's first creative exercise was to draw our menstrual cycles on a big white piece of paper on the floor. Drawing our cycles was a prompt to bring the participants and the first author closer together and a commitment to bring our menstrual cycles into the room. Each participant, including the first author, drew the length of their menstrual cycle with a chosen color. After that, all placed a coloured dot wherever in the cycle they considered themselves to be on the day of the workshop.

3.2.2 Sharing and Not Sharing Menstrual Memories. Then the participants were invited to write down two menstrual memories on a small piece of paper: one memory that they would like to share with the group, and one memory that they would like to keep secret. The first memory the participants shared openly in the group, and the second memory they folded and put in their pocket. The purpose of this division was for participants to reflect on their own boundaries for what they wanted to share, while still allowing private, perhaps difficult, experiences to be acknowledged.

3.2.3 Feldenkrais session on Breathing and Pelvis Movements. With inspiration from first-person experiences and existing Feldenkrais lessons by professional practitioners, the first author scripted and guided a Feldenkrais-inspired lesson directed to create awareness of breathing and pelvis movements. Inspired by research on touching and being in touch with the menstruating body [13], the lesson invited the participants to touch their chest, ribs and hips in order to come into deeper contact with their bodies. The participants lied on a yoga mat on their backs, and were told to only do comfortable movements. Before starting the Feldenkrais-inspired lesson, the participants filled out a body map sheet with colours and words explaining how they felt in their body (a method often used in soma design to capture feelings in the body before and after a bodily activity [68]). The first part of the lesson centered on breathing. Participants were invited to put their hands on their upper chest, their belly or their ribs, and to breathe deeply into their stomach. They were noticing how their breathing could fill up their chest on the top, the bottom, the sides and the back. The second part of the lesson centered on the pelvis bone, and encouraged explorations of the bones and the muscles. Participants were invited to feel their pelvis with their hands, touching the skin or pressing down in their flesh, and feel how strong their pelvis are as they move it around in circles. After the lesson, the participants were invited to fill out the second part of the body map sheet, and share their feelings in their body (before and after) with the rest of the group.

3.2.4 Aesthetic Laborations with Menarche Bits. With inspiration in aesthetic laborations (A-lab) [1], we invited the participants to explore Menarche Bits. Menarche Bits is a collection of shapechanging heat and soft robotic elements that can be combined with fabric. Placed against the body, the bits will stimulate, press, heat and massage the skin and inner muscles [57]. The A-lab is a guided method for tangible exploration of the qualities of a material [1]. The participants were divided in pairs of two of which one was guided to touch, squeeze, smell, listen to and look at Menarche Bits, and tell about their experience, while the other would take notes. Our aim with the exercise was for the participants to get 

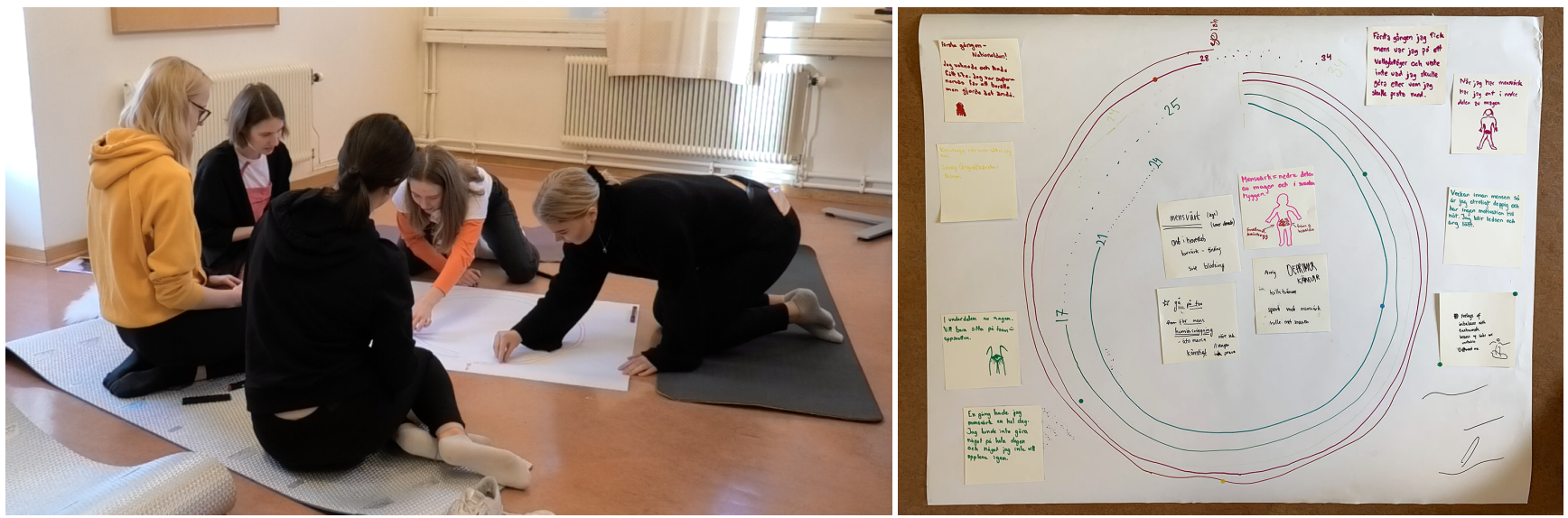

Figure 2: Participants drew their menstrual cycles and shared menstrual experiences (left), which were documented in a menstrual cycle "artwork" (right).

comfortable with Menarche Bits and to start developing a language for experiences and materials.

3.2.5 Designing Menstrual Technologies. We invited participants to design and prototype a menstrual technology. In the first workshop with 4 participants, participants were in the same pairs as in the A-lab session, while in the second workshop, participants designed for each other one-to-one. The participants were asked to address our design brief: Design a body-worn technology that engages with your unique experience of your menstrual cycle; 1 . Decide on a particular menstrual cycle experience to design for, 2. Use Menarche Bits as a prototyping tool for exploring possible designs. They could use fabric and design materials to sketch and build their designs. Then the participants were asked to present their designs and ask questions to each other. Lastly, the participants recorded a short video of themselves presenting their design concepts on their own smartphones, and sent it to the first author. We asked them to document it themselves to challenge the power imbalance between us researchers (behind the camera) recording them (in front of the camera).

\subsection{Workshop Documentation and Analysis}

We documented the workshop with video recording and through the second author's notes and photos. Participants documented the workshop through notes on their body maps and A-lab sheets and phone video recordings. We transcribed the participants' videos, and key moments from the video recording. We also did an interaction critique [5] on the design concepts as a way to analyse their interactions and aesthetics. Lastly, we wrote thick descriptions $[24,25]$ of the workshops' key moments and unfolding narratives, to initiate our understanding and interpretation of the data.

\section{WORKSHOP NARRATIVES}

The workshop resulted in insights on adolescents' experiences of menstrual cycles in sport, the use and experience of prototyping with Menarche Bits, and design concepts for menstrual technologies. We describe these insights through rich narratives of the workshops, inspired by the thick descriptions and with participants' quotes. We present three narratives 1) establishing a bond with participants, 2) designing for depressive and anxious feelings, and 3) designing for menstrual cramps. The narratives are written from the first author's perspective, using "I" and "me" to elevate the researcher's positionality and to situate the description in an intimate relation with the participants and the situation.

\subsection{Establishing a Bond with Participants}

In both workshops, I asked the participants what rules they wanted to make. The rules were "It should be fun", "You should be able to be open", "You should be able to feel comfortable", and "You should learn something". From this starting moment, the atmosphere was infused with humour, openness, comfort, and knowledge-exchange. Then I asked the participants to draw their menstrual cycle as a big open circle on the paper, depicting the length of their cycles from the minimum days to the maximum (Fig. 2). Insecure about what I meant, the participants seemingly waited for me to demonstrate it. I picked up a thick yellow pen, and from the top of the paper I started drawing my cycle. I drew with the pen slowly around the paper, first steadily in a rounded shape, stopped 75 percent around a circle, marked 24 days, and continued with dots to show that the cycle sometimes also approached 34 days. After me, the participants followed. Choosing colours, choosing their starting points. Then, with their whole body following their pen around on the paper, they drew their menstrual cycle. Finished with the first task, the large sheet of paper and the bold exaggerated movements manifested all our cycles layered on top of each other in different colours and different lengths. "It's an artwork", I said, and the participants laughed. As I asked them what they could say by looking at this picture, Wilma answered: "that it is very different". Eva added "It is very different from person to person but also for each person it is different. Sometimes it is 25 days, other times it is... different". After drawing the circle, I invited them to add a dot to where in the cycle they were right now. Some participants were quick, "Right here [plotting their dot on the paper] I stopped menstruating yesterday". Others had to think and some checked their phone to 
find the answer in their menstrual tracking application. Settled on paper between us, we had our menstrual cycles in the room. We knew where each other were. We started forming a bond and were ready to continue sharing more about of our personal menstrual experiences.

\subsection{Designing for Depressive and Anxious Feelings before Menstruation}

One narrative that unfolded soon after drawing our cycles was around feeling tired and anxious before menstruation. Ann and Astrid's menstrual tracking apps told them that within a few days their period would start. Astrid expressed that she was not sure if she was tired because it was still morning and she had a tough training the day before, or if it was because she would soon be menstruating. Wilma was certain: "I will have my menstruation soon and I have been feeling $a$ bit tired so I am in the end of my cycle". I asked the participants to write down and share one experience that had somehow been meaningful for them for how they experience their menstrual cycle. It could be a strong experience of menarche, or an experience that returned cycle after cycle. Lena wrote: "The week before the period, I am incredibly depressed and have no motivation for anything. I get sad and easily angry". Lena was the only person joining the workshop from her sport (basketball), yet she quickly felt comfortable among the three other participants, who were playing volleyball. Since participants in the first workshop were particularly expressive of their feelings of depression and anxiety and excited to design for these experiences, the rest of the narrative will focus on the first workshop.

Lena, Eva, Ida, and Wilma expressed how in the days before the bleeding they start to have "mood swings" and that they "don't want to do anything". Ida explained that she wants "to eat everything", and Wilma added: "The week before menstruating, I buy everything!". They explained that when they feel like that, they just want to lie in bed and not talk to anyone, just be alone. Ida explained that this week influenced her sports activities, because she gets angrier at her coach or team members during training. She expressed that she just wants to say "don't talk to me", but that it was okay since "everyone has bad days, so those you train with should understand it". The participants started to further discuss their experience of talking with team members, friends and coaches about their menstrual cycles. Wilma expressed: "Friends understand better than the coaches. The people we train with at school are the same age, so they experience the same as you. But the coaches don't understand, and especially because they're men. So I think that for them it's a bit difficult to talk about it. That is what I have experienced or felt when other people tried talking with them about it". The participants expressed that although team members should understand the "bad days" you may have leading up to the bleeding, it can still be difficult, because of the culture that coaches contribute to. Eva explained: "I try to not think about it, but when I think twice, I acknowledge that I get very irritated [before menstruation]. But I don't tell at the training".

Following this conversation between the participants, I invited them to explore Menarche Bits. Eva held the heat pads and silicone actuators in her hands and touched them with the tip of her fingers. Wilma placed them on her legs and arms, and felt them on the top of her jeans and directly on her arm's skin. Lena held them up to her ears to listen to them. While Eva noted down, Lena expressed her experiences. She referred to the heat pads and the silicone as "addictive", emphasizing that she wanted to keep touching and feeling them against her body. Wilma expressed that when touching the silicone actuator, it felt like "a beating heart" and sounded like "when someone is asleep". Then I asked them to reflect on what experience they wanted to design for. Eva and Lena decided to design for what they characterised as "the depressive and anxious feeling you can feel before menstruation, and the empty feeling that exists in the body". They sat down at the table and quickly found inspiration in making something that would be attached to the chest. They tried putting heat pads and silicone actuators on their chest. They decided on creating a triangle shape on the chest, and fastened it on a cotton blouse. Then they presented it, "The Calm-inator", to Wilma, Ida and me.

\subsection{Designing for the Pain of Menstrual Cramps}

Participants not only addressed the end of the menstrual cycle and its depressive and anxious feelings. By returning to the beginning of the workshops, we unfold a different narrative: this time about the first days of the menstrual cycle.

One experience that came up again and again in participants' accounts was menstrual cramps. As expressed by Ida: "My chosen experience is that I had menstrual pain a whole day and I took a painkiller but it didn't go away. And we should do something but I couldn't do it, because I had so much pain". Similarly, Ann's note said: "Recently I had menstruation for 5 days with a lot of blood and menstrual pain every day. I bleed through my napkins, tampons and pants + I couldn't move because I was in such a pain!!!". These descriptions point to the immense pain that menstrual cramps can cause. They also describe how menstrual pain can restrict one's actions and movements (i.e. not being able to do something, or not being able to move), but these first descriptions did not start to account for the felt experience of the pain.

After sharing experiences, I asked the participants to lay down comfortably on the yoga mats, and I guided a Feldenkrais-inspired lesson. After the Feldenkrais I invited the participants to reflect on how their experience with doing the Feldenkrais relate to their experience of menstrual cramps. Firstly, Wilma stated that it was difficult to remember, so "how can you describe the experience you don't have now". However, when I asked the participants to write down what they felt when having menstrual cramps, participants were quick at writing down some feelings. Maybe it was important that the participants had a space for privately articulating the experience, before sharing it in the group? Then I asked the participants to share their experience, and quickly it came to the surface that all have had experiences of menstrual pain but in different ways. Eva touched her lower stomach (an area that we moved and touched in the Feldenkrais) and said that she did not have cramps in the belly, but that she experience strong menstrual pain in her legs. Ida put her hands on her lower belly and explained that she has pain in the bottom of the stomach. If she has menstrual pain, she just wants to sit on the toilet all the time: "It's a contracted mass in the stomach, and down in the legs. And bloated". Participants had different 

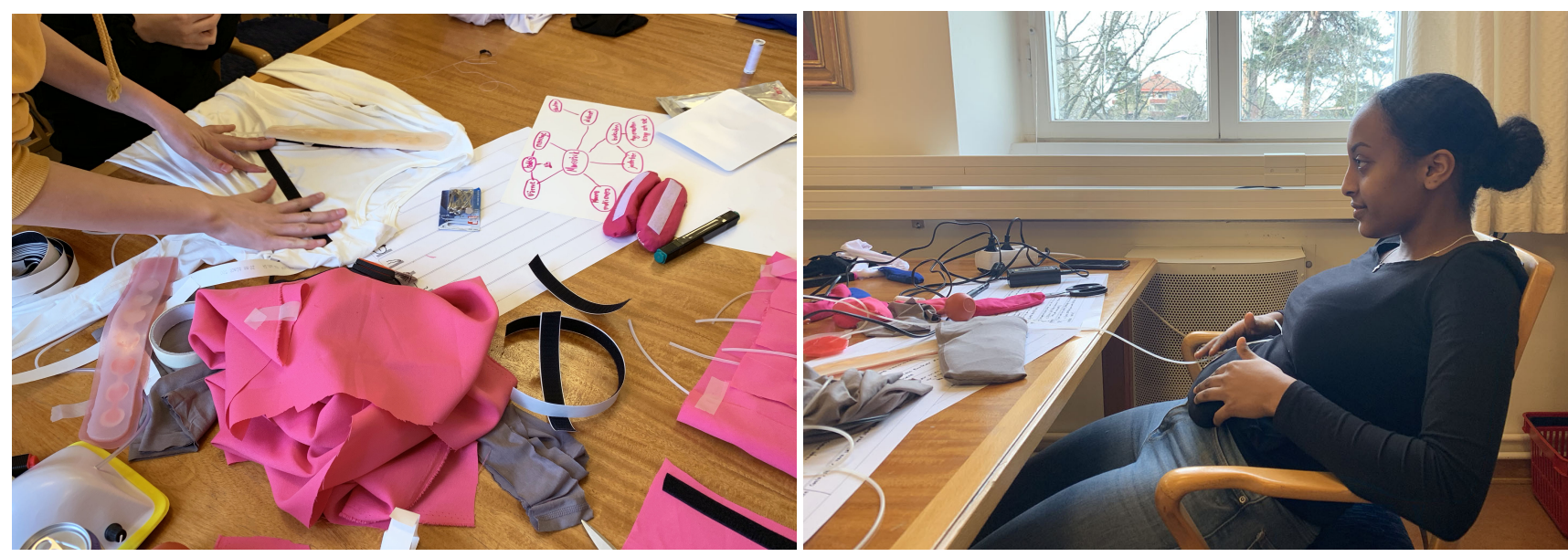

Figure 3: Participants used Menarche Bits to prototype wearables responding to their menstrual experiences, including a breathing shirt for anxious feelings (left), and a modular cushion for menstrual cramps (right).

strategies for responding to the pain caused by menstrual cramps. Some participants used painkillers, and some expressed that they actually enjoyed to move and do sport when having menstrual cramps. Wilma said: "I think it can be nice to train and move when you have menstruation. I don't know if it is because you don't think about it, but I have less pain when moving". Eva agreed: "it can be nice to train instead of lying down at home with menstrual pain. It doesn't stop if you just lie down at home and think about it". Ida shared that "it helps when I roll with my stomach", and demonstrated the rolling stomach movement, curiously articulating how the inner pain can be slightly changed by moving the flesh and muscles around the cramping uterus. Pain will not make the participants stay home or lie in bed, although it may be what they would sometimes prefer. As Lena explained: "Whether you have menstruation or not, you have to perform. At least I don't use it as an excuse if I have pain". It quickly became clear that there were also social factors that impact the decision to continuously do sport activities during menstrual cramps. The social factors include sports coaches, Lena explains: "I don't want them [the coaches] to think... for they don't understand because they don't go through it, so they cannot get that it fucking hurts. So I don't want to say "I have menstrual pain" or "I have pain in my stomach", but it does hurt". But the decision to do sport during menstrual cramps is also impacted by the fact that the participants are doing team sport. As Lena said: "You don't feel all good. You are not fully with your body, but you still train. And that is also because we are doing team sport". Eva added: "You have to perform because you also do it for other people - the team, your friends - and not just for your own sake. In team sport, you lift each other up. The responsibility is not just on yourself. If there is a championship, you cannot just skip because you have menstruation". The participants emphasized their passion for their sport: "You want to play! Not just for other people, but for yourself as well. Also when you have menstruation" (Ida). And Eva added: "so you tell yourself "it doesn't play a big role"."

4.3.1 Prototyping with Menarche Bits for Menstrual Cramps. In the second workshop, the participants (Ann, Astrid, and Elsa) interestingly put their experience of Menarche Bits in direct relation to menstrual cramps. Because of this curious relation the remaining narrative will unfold the second workshop. With curiosity, humour and care for each other, they explored the sensations of the heat and shape-change. As Elsa squeezed the heat pads, she said: "It is not such a nice material, but it could work for menstrual cramps". Further detailing the placement of the heat pads, Astrid said: "It has a nice shape. You can place it in the hip flexor", adding that it smells "like a normal wheat pillow" that can be heated and used for menstrual cramps. Astrid added that when touching the shape-changing silicone it creates "more relaxation in the muscle" where you have pain, but that "it is a bit cold, and I want it to be warmer like someone massaging me". While touching the heat pads and placing them on her stomach, Ann said that they "can be nicely shaped after your stomach". As Ann lightly touched the shape-changing silicone she said "it might be a bit cold on the stomach", reflecting that the heat pads with its calming distribution of heat against the skin would create a nicer feeling on her stomach. As she put it against her ear and listened to its sound "the mechanical sound of the pumps inflating and deflating the silicone air chambers " she said: "It has a lovely sound. The focus goes to the sound instead of the menstrual pain". While the three participants explored the Menarche Bits, they continuously described how the bits could be bigger, smaller, harder, softer, and bring more or less force towards the skin and flesh, but they did not explicitly explain why or for what purpose. However, as they started to engage with the design brief, it became clear that they already had started ideating on possible designs for menstrual cramps while they explored Menarche Bits on their bodies.

Ann, Astrid, and Elsa decided to design for menstrual cramps and bloated stomach in the first days of the menstrual cycle. I asked them to design for each other rather than themselves, and they started casually interviewing each other about their experience of menstrual cramps and bloated stomach. As they asked each other "where do you want the heat" or "how fast and intense do you want the massage", it became evident that menstrual cramps are not universal. They are different. Some experience them on the front of the pelvis, or on the side, or on the back. Some experience 


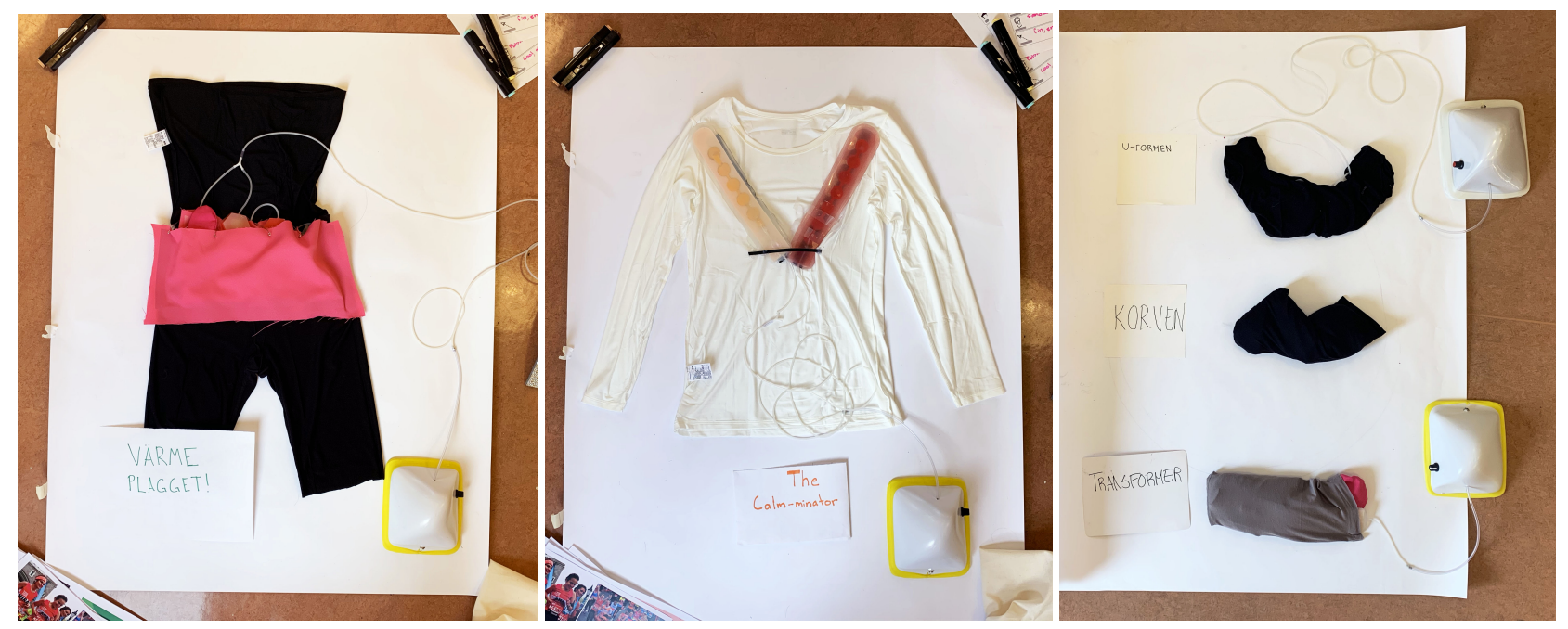

Figure 4: The participants' five design concepts of technologies for menstrual cycle experiences: Värme Plagget (left), The Calm-inator (middle), U-formen, Korven, and Transformer (right).

the cramps as spiking poking pain, others as a sustained pain that increases through time. Elsa, Ann and Astrid all carefully crafted their designs. They put fabric around Menarche Bits, and made pockets to put them into. They looked to each other's work and got inspired by how each managed to craft together soft materials, heat pads and shape-changing silicone. They taught each other how to sew and how the electronic pump worked. They continuously tried their designs on themselves, placing them on their lower stomach or neck, and they asked the other participants to try them too, to reassure that their combination of heat and shape-change would actually respond to the unique feelings of menstrual cramps expressed by the person they were designing for. Once finished, Elsa, Astrid and Ann sat on a row in front of their selfie camera, with the screen facing them so they could see themselves as they started to present their designs.

\section{MENSTRUAL CYCLE TECHNOLOGIES BY ADOLESCENTS}

The participants designed five technologies that respond to their experiences of menstrual cycles in sport (Fig 4). We use the participants' own rich descriptions to present the design concepts. The concepts demonstrate interactions with breathing, touch, modularity and rhythms, on intimate placements on the body, including the pelvis bone and the chest.

\section{1 "Värme Plagget" by Ida and Wilma}

Ida and Wilma designed "Värme Plagget" (heat garment): a modular, wearable garment for menstrual pain in the lower abdominal area (Fig. 4 left). Wilma explained: "We have made a garment suit that you can wear and use both if you're out for a walk, go to school, or even if you're at home, instead of having a heat pillow. In it there is a pocket in which you can put pulsating silicone things and rice cushions produce heat. And that will ease menstrual pain in the stomach". Ida added: "We think it's important with such a heat garment because you should be able to move and do what you want and not be hindered or constrained by menstruation". Emphasising the modularity of the garment, Wilma said: "There is both heat and movement to ease the pain in different ways based on what you need". The Heat Garment is designed as stretchable black bodysuit with the pink pockets placed inside the shorts. A number of pockets in various sizes and placements on the abdominal area allows the users to decide themselves if they to place heat or pulsation, and where they would like it.

\section{2 "The Calm-inator" by Eva and Lena}

Eva and Lena designed "The Calm-inator", a blouse that helps with breathing (Fig. 4 middle): "We have worked with depressive and difficult feelings before menstruation. It feels empty and tough. We thought that you often feel empty around the lungs and it can be hard to breathe. So we would place these massaging air pumps on the chest around the lungs, then it becomes calmer. You can decide yourself how fast it [the air inflation/deflation] should be from 1-7, should it be faster or slower, how much to you want to feel it. We tested it and tried to place it here [putting her hand on the chest], and we started breathing with the rhythm of it, so our design helps you to breathe. In that way it fills up an emptiness. We talked about that when you feel empty it feels like you don't exist. It feels like the body isn't there. But in this one, when you push then you feel like there is something there. That the body is there. You can place it as a triangle or like this, and with something going up here [shows that there should be silicone between the silicone shapes], so it can lie here and it becomes easier to breathe. But we also think that this idea with the bubble was smart, because when we tested them we thought this one was the best, because if there is just one then it feels stressful since there is too much focus on one point. But in this one, there are more bubbles, and that feels more comfortable". Lena further explained that the concept addresses the feeling of emptiness that comes before menstruation, and that the air inflation starting from the sternum and upwards to the shoulders would be a feelings of filling up the body. Eva 
elaborated: "Exactly. That you don't really feel your own body. So when you get a bit of resistance then you feel it". Lena explained that "you can use it when you are going to bed to calm down". And Eva added: "Or perhaps you can use it before training, so you can raise your pulse a bit, or while you train. It is like a shirt that you can wear when you are going out and do something you are afraid of, to calm you down". Eva and Lena's design suggests that the wearable design can make them more aware of their breathing and bring them closer to their body, and that this can help them with depressive and anxious feelings. The intended use context could both be in their home in bed, or before or after training, to make them ready for an activity.

\section{3 "U-formen" by Elsa}

Elsa designed a pulsating heat shape for menstrual pain on the lower stomach and hip bones, to be used at home: "My shape that I have made is called "U-formen" (The U-shape), and it looks like this [shows the design (Fig. 4 right top)]. It is made for putting on the stomach. And down here [pointing at the middle lower piece] I have put two heat cushions that will warm the lower part of the stomach, and on the sides I have put two vibraaa... pumps that pulsate. So you place it like this [puts it on the lower stomach] and then it pulsates here [presses on the hip bones] when you have menstrual pain, and down here it warms. So it should help with menstrual pain. It is easier to use it when you are home, sit on the couch or lie in bed. It is a bit complicated to bring it to school or somewhere. It is best used at home”.

\section{4 "Korven" by Astrid}

Astrid designed a mobile heat cushion for bloated stomach and menstrual cramps (Fig. 4 right middle): "I have made one that is called "Korven" (The Sausage). It looks like this and it is also used for menstrual pain, but also for bloated stomach before you have menstruation, but also during. It works by having two heat cushions in it, and you can fold it and easily put it in your bag and bring it everywhere. And then you either put it in the microwave to make it warm, or you can have it cold as well, and then there is a pressure that can make your stomach perhaps "go down" a bit [presses her stomach], I mean, less bloated, and first of all help with the pain of menstrual cramps. You can bring it with you easily in your bag, and you can use it before training or after training, and almost whenever. And you can use it if you have neck pain, or menstrual pain, or just pain in your legs. So yeah, you can use it for a lot!". Adding to Elsa's concept, Astrid emphasised how her design did not have to be used only at home, in relaxing positions such as in the bed or on the couch, but that it could be brought everywhere and be used almost whenever. In addition, Astrid's design worked for both bloated stomach and menstrual pain, but also for other kinds of muscle pain, e.g., in the neck or in the legs, the last being a place where other participants expressed they have menstrual pain but also pain from hard training.

\section{5 "Transformer" by Ann}

Ann designed a heat and pumping shape for menstrual pain (Fig. 4 right bottom): "Mine is called "Transformer". It should represent...".
Ann paused for a moment, then turned from words to demonstration: "It looks like this [Ann holds her design in front of the camera]. It is a kind of "to-go", so you can, as Astrid and Elsa say, use it when you go to training or when you go to school. In here I have put two heat cushions, that will give you heat, so you can put it in the microwave. And a pump that is all the way here [shows the pump's tubing to the silicone actuator], that you pump yourself or you can also use a machine. And Astrid "it [the design] was for her "she has very much pain in the middle of the stomach, and this helps with menstrual pain when you place it like this [puts in on the middle of the stomach]. And then you pump yourself [demonstrates by pumping the silicone with the small pump in her hand]". Ann's description of her design nicely showed the complexity of the design space in which her design operates. It points to a detailed understanding of where Astrid has pain ("in the middle of the stomach") and shows that menstrual pain can both be a problem when you want to attend training but also attend school. In her description, Ann builds on top of both Elsa and Astrid's concepts, adding details to how the design works with heat and pumping machines. She also incorporates an active element in the interaction, where the pumping of inflation/deflation is done by yourself. She based this design choice on her expression that when you have menstrual pain, you still want to be active. Pumping the actuators yourself draws the attention towards the mechanic and rhythmic pumping interaction which brings one closer to one's body, she explained.

\subsection{Concluding Remarks from Elsa, Astrid and Ann}

As we asked Elsa, Astrid, and Ann why their designs were important, Elsa expressed: "Why we have chosen to design these is because we dislike menstrual pain, which I think everyone does. We want to counteract that as well as we can. So that's why we have tried to make different shapes that can help against menstrual pain". Astrid added details on the specific problem in relation to sport: "Since we all three do football, do sport, we don't want menstrual cramps to hinder our performance on the football field. So, we want to prevent and ease menstrual pain as much as possible". Ann added: "I agree. And we chose these shapes because it's so simple to bring to the training, before training or after training". Astrid continued: "Almost whenever possible". Ann concluded and summarized: "Like it should decrease the pain".

\subsection{Reflections and Summary of Workshops}

Throughout the workshop, the participants' accounts of menstrual cramps and depressive and anxious feelings went from linguistic to embodied. At the beginning of the workshops, participants lightly touched and described their first menarche and menstrual experiences through words and stories. Then, during the Feldenkrais lesson, the participants became more aware of smaller areas on their body where such experience might be anchored. This made participants notice their bodies, and remember, perhaps even re-embody, past experiences. By experiencing heat and shape-changing on their bodies with Menarche Bits, participants became more embodied and started creating their own language and new movements to express their experiences. Finally, through placing materials on their bodies and through designing their own body-worn menstrual 
technologies, participants used a designerly exploratory practice to enact their body literacy and unique embodied knowledge as a way of responding to and transforming their menstrual experiences. The participants' concepts addressed menstrual experiences that returned to them in the beginning and end of each menstrual cycle: menstrual cramps and depressive and anxious feelings, and the experiences of pain and emptiness. Described through words such as "help", "prevent", "ease", "counteract", "minimize" and "decrease", the participants found designerly ways of transforming their experiences into preferred ones. Their designs showed how their menstrual experiences was intimately intertwined in their everyday life and could be used in all kinds of spaces and at all times of the day: in the sports club before training, on the bus on the way school, and in bed in the evening. Their design proposals address menstrual concerns in embodied and plural ways, where they with nuance and delicacy address each other's needs for ease of pain on different areas of the pelvis and calming breathing on the chest.

\section{DISCUSSION}

\subsection{Soma Design with Adolescents: Designing With and Close to the Newly Menstruating Body}

The workshops are the first to do participatory design with adolescents for menstrual health. As menstrual health can be intimate and involve private parts of the body, we put care into facilitating a workshop that was comfortable, fun and insightful for the adolescents. With inspiration from [22, 23, 52], we focused on nurturing relationships built on mutual trust and respect. We did this by supporting the participants' agency, letting them make rules for the workshops, facilitating the workshops through and in their school contexts, and inviting them to be experts in their own bodies and designers of their own technologies. We inspired participants' creativity through playful design activities and we allowed for constructive disagreement between participants as a way of fostering pluralism.

The workshops are also the first example of using soma design with adolescents, and more generally doing soma design in a participatory manner, where the participants are not experts in soma design. We were both curious and concerned about bringing adolescents into a soma design process on menstrual health. Curious because the participants as sport athletes are experts in a bodily practice, yet also concerned since the topic of menstrual health can be taboo and sensitive, also in Scandinavia. Soma design is characterised by bodily practices and being close to the body, often taking starting point in somatic experiences that people feel in the moment [32]. While people that menstruate are always somewhere in their menstrual cycle, menstrual experiences might not be easy to notice during a workshop, or they might be suppressed. Yet, the most crucial aspect of doing soma design in menstrual health is that the participants deeply engage with their bodies and experiences of menstrual cycles. From talking about them, to touching them, to exploring them, to responding to them. We built up this trajectory through the workshop's structure, the use of Menarche Bits, and the creation of a cozy and comfortable atmosphere. Whereas previous work has for instance used humour to cross the taboo of intimate body parts [3] and fluids [27, 56], or cultural euphemisms to teach students about HIV [50], we focused on creating a cosy and comfortable atmosphere to engage with the sensitive, sometimes taboo area of menstruation. We created this with soft materials in the room, sitting and rolling on the floor, a close distance between bodies, and a mutual respect created through making rules and setting boundaries.

With the foundation of a cosy and comfortable atmosphere, the success of the workshop lied in the workshop's format and the use of Menarche Bits. The use of a toolkit approach had a crucial impact for the trajectory from a linguistic to an embodied engagement with menstrual experiences. Menarche Bits, as an open-ended prototyping toolkit, allowed participants to explore and express their unique experiences. Firstly, since there was no universal, right way of using Menarche Bits, the toolkit opened up for designing for diverse menstrual experiences and thus supported pluralism although we found that the focus on the body mainly inspired design for menstrual cramps. Secondly, the prototyping and embodied ideation where Menarche Bits was placed on the body supported the enactment of the participants' own body literacy. Instead of drawing on textbook knowledge, which has been argued to be insufficient for adolescents' menstrual health education [62], participants were invited to be(come) experts in their own bodies, drawing on their own body as inspiration for design of menstrual technologies. E.g., Eva and Lena developed a nuanced vocabulary and exploration of their own bodies, as they tried placing the actuators on their chest area to, as they express it, literally fill up their body with air through breathing, and affectively make them feel like "their body is there", that they are not empty. Their breathing shirt for pre-menstrual depressive feelings is an example of using experiential qualities from soma design, such as breathing, touching and movement $[13,34,49]$, to both express an emptiness in the body and respond to this by creating resistance on the body. One challenge for doing soma design on menstrual cycles was that the participants would not necessarily have somatic experiences of menstrual cycles during the workshop. E.g., Wilma expressed that they did not have menstrual cramps during the workshop, and Eva said that she did not feel such cramps at all, so how could they design for it? While this was considered difficult at first, when Ann, Astrid and Elsa started placing materials on their bodies, they were able to remember where they felt the menstrual cramps. We found that the workshop format and the use of Menarche Bits allowed participants to get back into their bodily menstrual experiences. The participants were able to re-enact, remember, and better understand the nuances of their own menstrual experiences through the exchange of stories and felt experiences of menstruation, through the Feldenkrais lesson's focus on intimate movement, and through exploring materials including Menarche Bits on their bodies. This body literacy that slowly built up during the workshop also allowed them to better understand others' experiences that may be different from their own. We saw this when Ann with precision were able to design for and describe the experience of Astrid's menstrual pain. Thus, even if the participants were not having menstrual cramps or anxiety during the workshop, they were able to design - with a deep sensibility - for these experiences because of the workshop's somatic practices and material prototyping that took starting point in their own bodies. 
In summary, we contribute three findings on combining soma design and participatory design with adolescents in the application area of menstrual cycles. Firstly, we argue that a cosy and comfortable atmosphere is crucial for designing in sensitive areas like menstrual health, for adolescents to dismantle the menstrual stigma and express their felt experiences of menstrual cycles. Secondly, we argue that somatic practices and ideation can bring an intimacy and closeness to the menstruating body, memorising and bringing forth (past) experiences in the body by touching and moving the body. Thirdly, we argue that a toolkit approach that support embodiment and plurality can nuance adolescents' sensitivities for their own menstruating bodies and how to design for them, but also better understand and design for other menstruators' bodies. We argue that this design approach is a strong path forward for adolescents to develop their body literacy on menstrual health by drawing on and becoming comfortable in their own bodies.

\subsection{Future Menstrual Technologies for Movements, Embodiment and Body Literacy}

The participants' design concepts show that menstrual technologies can be much more and different than self-tracking and data-driven technologies, that support prediction, management, and control of the menstruating body. Rather than concealing menstruation and reproducing the menstrual stigma, the participants' accounts and design concepts support Bobel's new vision for a menstrual activism termed "radical menstrual embodiment", which considers the value of menstruation in public and brings forward the bloody, messy, embodied version of menstrual cycles [10]. By drawing on qualities of embodiment and their own body literacy, the participants imagined and designed novel body-worn and shape-changing technologies. These designs supported a close attending to the menstruating body and ways of touching [13] and being-with the body, that made the participants feel that they were "in their body"; that their body was not a separate entity from their mind but part of their whole soma. In "The Calm-inator", breathing was used as in interaction to bring one closer to their body. As expressed by Eva and Lena, by breathing-with the wearable inflation/deflation technology, one may feel like being "filled" (back) up in their body. Similarly, Ann's "Transformer" implied that by pumping the massaging units oneself, one may come closer to the body, and in similar rhythmic patterns as in breathing, one may use the body's own movements as a transformer of the menstrual experience. While these may be small movements - deep breathing or hand pumping they are still movements that reconfigure the menstruating body as an active, moving body, hereby resisting narratives of limitations and restrictions caused by menstruation. The participants' proposals for menstrual technologies elevated the menstruating body and its changes during the different phases in the menstrual cycle: how the body feels and moves and how it comes to know through movement. While current menstrual cycle technologies are often constrained to the screen [15] or in the spaces externally to the menstruating body $[18,31]$, with exceptions such as (smart) menstrual hygiene products $[44,56]$, we are proposing a design agenda for menstrual technologies that are interacting close-to-thebody, on the skin and in the flesh of the menstruating body that meets the world. Designing menstrual technologies that interact intimately with the menstruating body will support qualities of embodiment, movement, and body literacy. They will bring people who menstruate closer to their bodies, noticing it, and caring for it, rather than accommodating it, suppressing it or internalizing the stigma of it. The participants' designs expressed qualities of pluralism through modularity, and embodiment through actuation close-to-the-body. We see these qualities and visions crucial to consider, embrace and elevate in future menstrual technologies, and believe that these qualities can both inspire more comfort and confidence in menstruating bodies and support menstrual advocacy.

However, while doing this research, we and the participants were continuously moving in a tension between appreciating and accepting the menstruating body and all its mess and trouble [55], and wanting to counteract, minimize or even "fix" the pain and discomfort related to menstruation. But we believe that technologies do not need to be situated on either extreme of this spectrum. Menstrual technologies do not have to be framed as a "solution" that fixes the menstruating body, nor do they have to actively resist the transformation of menstrual experiences. Rather than working in the dichotomy of this tension, we want to create technologies that support body literacy and expression of felt experiences, as this can help participants - and people who menstruate, more generally - to develop acceptance of one's body, also when acceptance implies further action.

Lastly, we suggest that designing technologies that support such body literacy can not only be beneficial for individual menstruators and in their communities, such as high schools and sport clubs, but also in menstrual health education. E.g., could we imagine that instead of delivering menstrual health education with the use of digital platforms [60], games [35], or external representations of the uterus [58], which mainly build on textbook knowledge, that such education could be supported with body-worn or body-based technologies that instead of textbook knowledge focus on adolescents' own bodies, in order to develop their own body literacy? While participants in our workshops expressed the menstrual stigma they experience in their sport clubs and schools, they were comfortable in our workshops and enjoyed engaging their own bodies. Thus we see opportunities for extending this research also in educational contexts.

\section{FUTURE WORK}

We aim to further develop the participants' design concepts into high fidelity prototypes that can be deployed with the same adolescents for a longer time to better understand their use and experience through several menstrual cycles. Secondly, we wish to understand how design workshops and toolkits like Menarche Bits can do menstrual advocacy and inspire body literacy in educational contexts beyond Scandinavian, such as in Tuli et al.'s research on India's menstrual health education [62]. While our research shows a path for future menstrual technologies, we also acknowledge the gaps in terms of which bodies and communities have been designed with and for, since we were only successful in recruiting able-bodied cisgender girls. More work and time need to go into partnering with trans and genderqueer adolescents and communities, and young menstruators with disabilities. Such experiences are crucial to fully 
grasp and pursue the opportunities for designing technology that truly supports embodiment and pluralism in menstrual health.

\section{CONCLUSION}

By designing menstrual technologies with adolescents, we found that there is a need to make space for menstrual cycles in adolescence. While menstrual health education is crucial for understanding the body, we must not get stuck at the level of providing knowledge. We also need to provide adolescents with a space to be with their bodies as they are changing, to acknowledge these changes, and perhaps even appreciate them and learn from them. Soma design and participatory design can be part of such a movement. We are not creating menstrual technologies to put the responsibility for social change and resistance to societal norms onto the individual. Rather, we are using the design of menstrual technologies to make space for conversations, knowledge exchange and for simply being with the menstruating body. We believe that by designing technologies and spaces in institutions that support adolescents to listen to and care for their newly-menstruating body, we can create freer movements that will positively impact them in years to come. We call for menstrual technologies that invite menstruators to make a movement. From literally making movements with the menstruating body: touching it, noticing its experiences and molding these into soothing, comfortable ones, to conceptually and structurally making a movement: making spaces for conversations and advocating for menstrual body literacy in the communities where adolescents' menstrual experiences are shaped and enacted.

\section{ACKNOWLEDGMENTS}

We want to deeply thank the participants in these workshops and acknowledge their important contribution to this research. Also thank you to the Interaction Design team at MID, KTH, especially to Ozgun Kilic Afsar, Nadia Campo Woytuk, Anna Ståhl, and Kristina Höök for your support and feedback. This work was partially funded by the Swedish Research Council project 2017-05133.

\section{REFERENCES}

[1] Cheryl Akner Koler. 2007. Form \& Formlessness: Questioning aesthetic abstraction through art projects, cross-disciplinary studies and product design education. Axl Books, Stockholm. http://urn.kb.se/resolve?urn=urn:nbn:se:konstfack:diva- 6000

[2] Teresa Almeida, Rob Comber, and Madeline Balaam. 2016. HCI and Intimate Care As an Agenda for Change in Women's Health. In Proceedings of the 2016 CHI Conference on Human Factors in Computing Systems (CHI '16). ACM, New York, NY, USA, 2599-2611. https://doi.org/10.1145/2858036.2858187

[3] Teresa Almeida, Rob Comber, Gavin Wood, Dean Saraf, and Madeline Balaam 2016. On Looking at the Vagina Through Labella. In Proceedings of the $2016 \mathrm{CH}$ Conference on Human Factors in Computing Systems (CHI '16). ACM, New York, NY, USA, 1810-1821. https://doi.org/10.1145/2858036.2858119

[4] Madeline Balaam, Nadia Campo Woytuk, Marianela Ciolfi Felice, Ozgun Kilic Afsar, Anna Ståhl, and Marie Louise Juul Søndergaard. 2020. Intimate touch Interactions 27, 6 (Nov. 2020), 14-17. https://doi.org/10.1145/3427781

[5] Jeffrey Bardzell. 2011. Interaction criticism: An introduction to the practice. Interacting with Computers 23, 6 (Nov. 2011), 604-621. https://doi.org/10.1016/j intcom.2011.07.001 Publisher: Oxford Academic.

[6] Jeffrey Bardzell and Shaowen Bardzell. 2018. "My Peaceful Vagina Revolution:" A Theory of a Design: From Usability to Enjoyment. In Funology 2. Springer International Publishing, The US, 77-91. https://doi.org/10.1007/978-3-31968213-6_6

[7] Jeffrey Bardzell, Shaowen Bardzell, and Lone Koefoed Hansen. 2015. Immodest Proposals: Research Through Design and Knowledge. In Proceedings of the 33rd Annual ACM Conference on Human Factors in Computing Systems (CHI '15). ACM New York, NY, USA, 2093-2102. https://doi.org/10.1145/2702123.2702400
[8] Shaowen Bardzell. 2010. Feminist HCI: Taking Stock and Outlining an Agenda for Design. In Proceedings of the SIGCHI Conference on Human Factors in Computing Systems (CHI '10). ACM, New York, NY, USA, 1301-1310. https://doi.org/10. $1145 / 1753326.1753521$

[9] Wolmet Barendregt, Mathilde M. Bekker, Peter Börjesson, Eva Eriksson, and Olof Torgersson. 2016. The Role Definition Matrix: Creating a Shared Understanding of Children's Participation in the Design Process. In Proceedings of the The 15th International Conference on Interaction Design and Children (IDC '16). ACM, New York, NY, USA, 577-582. https://doi.org/10.1145/2930674.2935999 event-place: Manchester, United Kingdom.

[10] Chris Bobel and Breanne Fahs. 2020. From Bloodless Respectability to Radical Menstrual Embodiment: Shifting Menstrual Politics from Private to Public. Signs: Journal of Women in Culture and Society 45, 4 (June 2020), 955-983. https: //doi.org/10.1086/707802

[11] G. Bruinvels, R. J. Burden, A. J. McGregor, K. E. Ackerman, M. Dooley, T. Richards, and C. Pedlar. 2017. Sport, exercise and the menstrual cycle: where is the research? British Journal of Sports Medicine 51, 6 (March 2017), 487-488. https://doi.org/ 10.1136/bjsports-2016-096279 Publisher: BMJ Publishing Group Ltd and British Association of Sport and Exercise Medicine Section: Editorial.

[12] Susanne Bødker and Morten Kyng. 2018. Participatory Design That Matters-Facing the Big Issues. ACM Trans. Comput.-Hum. Interact. 25, 1 (Feb. 2018), 4:1-4:31. https://doi.org/10.1145/3152421

[13] Nadia Campo Woytuk, Marie Louise Juul Søndergaard, Marianela Ciolfi Felice, and Madeline Balaam. 2020. Touching and Being in Touch with the Menstruating Body. In Proceedings of the 2020 CHI Conference on Human Factors in Computing Systems (CHI '20). Association for Computing Machinery, New York, NY, USA, 1-14. https://doi.org/10.1145/3313831.3376471

[14] Allison Druin. 2002. The role of children in the design of new technology. Behaviour \& Information Technology 21, 1 (Jan. 2002), 1-25. https: //doi.org/10.1080/01449290110108659 Publisher: Taylor \& Francis eprint: https://doi.org/10.1080/01449290110108659.

[15] Daniel A. Epstein, Nicole B. Lee, Jennifer H. Kang, Elena Agapie, Jessica Schroeder, Laura R. Pina, James Fogarty, Julie A. Kientz, and Sean A. Munson. 2017. Examining Menstrual Tracking to Inform the Design of Personal Informatics Tools. Proceedings of the SIGCHI conference on human factors in computing systems. CHI Conference 2017 (May 2017), 6876-6888. https://doi.org/10.1145/3025453.3025635

[16] Miranda A. Farage and Howard I. Maibach (Eds.). 2006. The Vulva: Anatomy, Physiology, and Pathology (1 edition ed.). CRC Press, New York.

[17] Margaret Flemings, Shanzay Kazmi, Rachel Pak, and Orit Shaer. 2018. Crimson Wave: Shedding Light on Menstrual Health. In Proceedings of the Twelfth International Conference on Tangible, Embedded, and Embodied Interaction (TEI '18). Association for Computing Machinery, New York, NY, USA, 343-348. https://doi.org/10.1145/3173225.3173292

[18] Sarah Fox, Noura Howell, Richmond Wong, and Franchesca Spektor. 2019. Vivewell: Speculating Near-Future Menstrual Tracking through Current Data Practices. In Proceedings of the 2019 on Designing Interactive Systems Conference (DIS '19). Association for Computing Machinery, San Diego, CA, USA, 541-552. https://doi.org/10.1145/3322276.3323695

[19] Sarah E. Fox, Rafael M.L. Silva, and Daniela K. Rosner. 2018. Beyond the Prototype: Maintenance, Collective Responsibility, and Public IoT. In Proceedings of the 2018 Designing Interactive Systems Conference (DIS '18). ACM, New York, NY, USA, 21-32. https://doi.org/10.1145/3196709.3196710

[20] Sarah E. Frank. 2020. Queering Menstruation: Trans and Non-Binary Identity and Body Politics. Sociological Inquiry 90, 2 (2020), 371-404. https://doi.org/10.1111/ soin.12355 eprint: https://onlinelibrary.wiley.com/doi/pdf/10.1111/soin.12355.

[21] S. E. Frank and Jac Dellaria. 2020. Navigating the Binary: A Visual Narrative of Trans and Genderqueer Menstruation. In The Palgrave Handbook of Critical Menstruation Studies, Chris Bobel, Inga T. Winkler, Breanne Fahs, Katie Ann Hasson, Elizabeth Arveda Kissling, and Tomi-Ann Roberts (Eds.). Springer, Singapore, 69-76. https://doi.org/10.1007/978-981-15-0614-7_7

[22] Christopher Frauenberger, Judith Good, and Alyssa Alcorn. 2012. Challenges, Opportunities and Future Perspectives in Including Children with Disabilities in the Design of Interactive Technology. In Proceedings of the 11th International Conference on Interaction Design and Children (IDC '12). ACM, New York, NY, USA, 367-370. https://doi.org/10.1145/2307096.2307171 event-place: Bremen, Germany.

[23] Christopher Frauenberger, Katta Spiel, Laura Scheepmaker, and Irene Posch. 2019. Nurturing Constructive Disagreement - Agonistic Design with Neurodiverse Children. In Proceedings of the 2019 CHI Conference on Human Factors in Computing Systems. ACM, New York, NY, USA, 271. https://doi.org/10.1145/3290605.3300501

[24] Melissa Freeman. 2014. The Hermeneutical Aesthetics of Thick Description. Qualitative Inquiry 20, 6 (July 2014), 827-833. https://doi.org/10.1177/ 1077800414530267 Publisher: SAGE Publications Inc.

[25] Clifford Geertz. 1973. Thick Description: Towards an Interpretive Theory of Culture. In The Interpretation of Cultures, Clifford Geertz (Ed.). Basic Books, New York, NY, USA.

[26] Elizabeth Grosz. 1994. Volatile Bodies: Toward a Corporeal Feminism (first edition ed.). Indiana University Press, Bloomington. 
[27] Karey Helms. 2019. Do You Have to Pee? A Design Space for Intimate and Somatic Data. In Proceedings of the 2019 on Designing Interactive Systems Conference (DIS '19). Association for Computing Machinery, New York, NY, USA, 1209-1222. https://doi.org/10.1145/3322276.3322290

[28] Simone D. Herzberg, Makalapua L. Motu'apuaka, William Lambert, Rongwei Fu, Jacqueline Brady, and Jeanne-Marie Guise. 2017. The Effect of Menstrual Cycle and Contraceptives on ACL Injuries and Laxity: A Systematic Review and Metaanalysis. Orthopaedic fournal of Sports Medicine 5, 7 (July 2017), 2325967117718781. https://doi.org/10.1177/2325967117718781 Publisher: SAGE Publications Inc.

[29] Sarah Homewood, Harvey Bewley, and Laurens Boer. 2019. Ovum: Designing for Fertility Tracking as a Shared and Domestic Experience. In Proceedings of the 2019 on Designing Interactive Systems Conference (DIS '19). Association for Computing Machinery, San Diego, CA, USA, 553-565. https://doi.org/10.1145/ 3322276.3323692

[30] Sarah Homewood, Amanda Karlsson, and Anna Vallgårda. 2020. Removal as a Method: A Fourth Wave HCI Approach to Understanding the Experience of SelfTracking. In Proceedings of the 2020 ACM Designing Interactive Systems Conference (DIS '20). Association for Computing Machinery, New York, NY, USA, 1779-1791. https://doi.org/10.1145/3357236.3395425

[31] Sarah Homewood and Anna Vallgårda. 2020. Putting Phenomenological Theories to Work in the Design of Self-Tracking Technologies. In Proceedings of the 2020 ACM Designing Interactive Systems Conference (DIS '20). Association for Computing Machinery, New York, NY, USA, 1833-1846. https://doi.org/10.1145/3357236. 3395550

[32] Kristina Höök. 2018. Designing with the Body: Somaesthetic Interaction Design. The MIT Press, Cambridge, Massachusetts.

[33] Kristina Höök, Sara Eriksson, Marie Louise Juul Søndergaard, Marianela Ciolfi Felice, Nadia Campo Woytuk, Ozgun Kilic Afsar, Vasiliki Tsaknaki, and Anna Ståhl 2019. Soma Design and Politics of the Body. In Proceedings of the Halfway to the Future Symposium 2019 (HTTF 2019). Association for Computing Machinery, New York, NY, USA, 1-8. https://doi.org/10.1145/3363384.3363385

[34] Kristina Höök, Martin P. Jonsson, Anna Ståhl, and Johanna Mercurio. 2016. Somaesthetic Appreciation Design. In Proceedings of the 2016 CHI Conference on Human Factors in Computing Systems (CHI '16). Association for Computing Machinery, San Jose, California, USA, 3131-3142. https://doi.org/10.1145/2858036. 2858583

[35] Minal Jain and Pradeep Yammiyavar. 2015. Game based learning tool seeking peer support for empowering adolescent girls in rural Assam. In Proceedings of the 14th International Conference on Interaction Design and Children (IDC '15). Association for Computing Machinery, Boston, Massachusetts, 275-278. https://doi.org/10.1145/2771839.2771895

[36] Os Keyes, Burren Peil, Rua M. Williams, and Katta Spiel. 2020. Reimagining (Women's) Health: HCI, Gender and Essentialised Embodiment. ACM Transactions on Computer-Human Interaction 27, 4 (Aug. 2020), 25:1-25:42. https: //doi.org/10.1145/3404218

[37] Necip Fazil Kishali, Osman Imamoglu, Dursun Katkat, Tulin Atan, and Pelin Akyol. 2006. Effects of menstrual cycle on sports performance. The International Journal of Neuroscience 116, 12 (Dec. 2006), 1549-1563. https://doi.org/10.1080/ 00207450600675217

[38] Julia Kristeva. 1982. Powers of Horror: An Essay on Abjection (reprint edition ed.) Columbia University Press, New York.

[39] Joselyn McDonald, Siyan Zhao, Jen Liu, and Michael L. Rivera. 2018. MaxiFab: Applied Fabrication to Advance Period Technologies. In Proceedings of the 2018 ACM Conference Companion Publication on Designing Interactive Systems (DIS '18 Companion). Association for Computing Machinery, New York, NY, USA, 13-19. https://doi.org/10.1145/3197391.3205405

[40] Marianne E. McPherson and Lauren Korfine. 2004. Menstruation across time: menarche, menstrual attitudes, experiences, and behaviors. Women's Health Issues: Official Publication of the facobs Institute of Women's Health 14, 6 (Dec. 2004), 193-200. https://doi.org/10.1016/j.whi.2004.08.006

[41] Daphne Menheere, Carine Lallemand, Ilse Faber, Jesse Pepping, Bram Monkel, Stella Xu, and Steven Vos. 2019. Graceful Interactions and Social Support as Motivational Design Strategies to Encourage Women in Exercising. In Proceedings of the Halfway to the Future Symposium 2019 (HTTF 2019). Association for Computing Machinery, New York, NY, USA, 1-10. https://doi.org/10.1145/3363384. 3363404

[42] Geraldine Moreno-Black and Helen Vallianatos. 2005. Young Women's Experiences of Menstruation and Athletics. Women's Studies Quarterly 33, 1/2 (2005), 50-67. https://www.jstor.org/stable/40005501

[43] Elena Márquez Segura, Laia Turmo Vidal, Luis Parrilla Bel, and Annika Waern. 2019. Circus, Play and Technology Probes: Training Body Awareness and Control with Children. In Proceedings of the 2019 on Designing Interactive Systems Conference (DIS '19). ACM, New York, NY, USA, 1223-1236. https://doi.org/10. 1145/3322276.3322377 event-place: San Diego, CA, USA.

[44] Sarah Ng, Shaowen Bardzell, and Jeffrey Bardzell. 2020. The Menstruating Entrepreneur Kickstarting a New Politics of Women's Health. ACM Transaction on Computer-Human Interaction 27, 4 (Aug. 2020), 21:1-21:25. https://doi.org/10. $1145 / 3397158$
[45] Stina Nylander, Jakob Tholander, Florian Mueller, and Joe Marshall. 2014. HCI and Sports. In CHI '14 Extended Abstracts on Human Factors in Computing Systems (CHIEA '14). ACM, New York, NY, USA, 115-118. https://doi.org/10.1145/2559206. 2559223

[46] Carol J. Pierman. 2005. Editorial. Women's Studies Quarterly 33, 1/2 (2005), 6-16. https://www.jstor.org/stable/40005498

[47] Gun Rembeck. 2008. The Winding Road to Womanhood: Adolescents' attitudes towards menstruation, womanhood and sexual health - observational and interventional studies. University of Gothenburg, Sweden. https://gupea.ub.gu.se/ handle/2077/10121

[48] Camilla Mørk Røstvik. 2020. Mother Nature as Brand Strategy: Gender and Creativity in Tampax Advertising 2007-2009. Enterprise \& Society 21, 2 (June 2020), 413-452. https://doi.org/10.1017/eso.2019.36 Publisher: Cambridge University Press.

[49] Thecla Schiphorst. 2009. Soft(N): Toward a Somaesthetics of Touch. In CHI '09 Extended Abstracts on Human Factors in Computing Systems (CHI EA '09). ACM, New York, NY, USA, 2427-2438. https://doi.org/10.1145/1520340.1520345 event-place: Boston, MA, USA.

[50] Piya Sorcar, Benjamin Strauber, Prashant Loyalka, Neha Kumar, and Shelley Goldman. 2017. Sidestepping the Elephant in the Classroom: Using Culturally Localized Technology To Teach Around Taboos. In Proceedings of the 2017 CHI Conference on Human Factors in Computing Systems (CHI '17). Association for Computing Machinery, New York, NY, USA, 2792-2804. https://doi.org/10.1145/ 3025453.3025958

[51] Katta Spiel. 2019. Body-positive computing as a means to counteract normative biases in fitness trackers. XRDS: Crossroads, The ACM Magazine for Students 25, 4 (July 2019), 34-37. https://doi.org/10.1145/3331065

[52] Katta Spiel, Emeline Brulé, Christopher Frauenberger, Gilles Bailly, and Geraldine Fitzpatrick. 2018. Micro-ethics for Participatory Design with Marginalised Children. In Proceedings of the 15th Participatory Design Conference: Full Papers - Volume 1 (PDC '18). ACM, New York, NY, USA, 17:1-17:12. https: //doi.org/10.1145/3210586.3210603 event-place: Hasselt and Genk, Belgium.

[53] Katta Spiel, Os Keyes, and Pınar Barlas. 2019. Patching Gender: Non-binary Utopias in HCI. In Extended Abstracts of the 2019 CHI Conference on Human Factors in Computing Systems (CHI EA '19). ACM, New York, NY, USA, alt05:1alt05:11. https://doi.org/10.1145/3290607.3310425 event-place: Glasgow, Scotland Uk.

[54] Linda Steele and Beth Goldblatt. 2020. The Human Rights of Women and Girls with Disabilities: Sterilization and Other Coercive Responses to Menstruation. In The Palgrave Handbook of Critical Menstruation Studies, Chris Bobel, Inga T. Winkler, Breanne Fahs, Katie Ann Hasson, Elizabeth Arveda Kissling, and TomiAnn Roberts (Eds.). Springer, Singapore, 77-91. https://doi.org/10.1007/978-98115-0614-7_8

[55] Marie Louise Juul Søndergaard. 2020. Troubling Design: A Design Program for Designing with Women's Health. ACM Transactions on Computer-Human Interaction 27, 4 (Aug. 2020), 24:1-24:36. https://doi.org/10.1145/3397199

[56] Marie Louise Juul Søndergaard and Lone Koefoed Hansen. 2016. PeriodShare: A Bloody Design Fiction. In Proceedings of the 9th Nordic Conference on HumanComputer Interaction (NordiCHI '16). ACM, New York, NY, USA, 113:1-113:6. https://doi.org/10.1145/2971485.2996748

[57] Marie Louise Juul Søndergaard, Ozgun Kilic Afsar, Marianela Ciolfi Felice, Nadia Campo Woytuk, and Madeline Balaam. 2020. Designing with Intimate Materials and Movements: Making "Menarche Bits". In Proceedings of the 2020 ACM Designing Interactive Systems Conference (DIS '20). Association for Computing Machinery, New York, NY, USA, 587-600. https://doi.org/10.1145/3357236.3395592

[58] Bonnie Tran and Lee Na Choi. 2018. Menstrual Maze: A Toy Exploring Public Engagement in Menstrual Health Education. In Extended Abstracts of the 2018 CHI Conference on Human Factors in Computing Systems (CHI EA '18). Association for Computing Machinery, Montreal QC, Canada, 1-6. https://doi.org/10.1145/ 3170427.3180649

[59] Vasiliki Tsaknaki, Madeline Balaam, Anna Ståhl, Pedro Sanches, Charles Windlin, Pavel Karpashevich, and Kristina Höök. 2019. Teaching Soma Design. In Proceedings of the 2019 on Designing Interactive Systems Conference (DIS '19). Association for Computing Machinery, New York, NY, USA, 1237-1249. https: //doi.org/10.1145/3322276.3322327

[60] Anupriya Tuli, Shaan Chopra, Neha Kumar, and Pushpendra Singh. 2018. Learning from and with Menstrupedia: Towards Menstrual Health Education in India. Proceedings of the ACM on Human-Computer Interaction 2, CSCW (Nov. 2018), 174:1-174:20. https://doi.org/10.1145/3274443

[61] Anupriya Tuli, Shaan Chopra, Pushpendra Singh, and Neha Kumar. 2020. Menstrual (Im)Mobilities and Safe Spaces. In Proceedings of the 2020 CHI Conference on Human Factors in Computing Systems (CHI '20). Association for Computing Machinery, Honolulu, HI, USA, 1-15. https://doi.org/10.1145/3313831.3376653

[62] Anupriya Tuli, Shruti Dalvi, Neha Kumar, and Pushpendra Singh. 2019. "It's a girl thing": Examining Challenges and Opportunities around Menstrual Health Education in India. ACM Transactions on Computer-Human Interaction (TOCHI) 26, 5 (July 2019), 29:1-29:24. https://doi.org/10.1145/3325282 
[63] Laia Turmo Vidal, Elena Márquez Segura, Luis Parrilla Bel, and Annika Waern. 2020. Training Body Awareness and Control with Technology Probes: A Portfolio of Co-Creative Uses to Support Children with Motor Challenges. In Proceedings of the Fourteenth International Conference on Tangible, Embedded, and Embodied Interaction (TEI '20). Association for Computing Machinery, New York, NY, USA, 823-835. https://doi.org/10.1145/3374920.3375002

[64] Jennifer Weiss-Wolf. 2017. Periods Gone Public: Taking a Stand for Menstrual Equity. Arcade, New York.

[65] Lisbeth Wikström-Frisén. 2016. Training and hormones in physically active women : with and without oral contraceptive use. Ph.D. Dissertation. Umeå University, Umeå, Sweden. http://urn.kb.se/resolve?urn=urn:nbn:se:umu:diva-124842

[66] Danielle Wilde, Anna Vallgårda, and Oscar Tomico. 2017. Embodied Design Ideation Methods: Analysing the Power of Estrangement. In Proceedings of the 2017 CHI Conference on Human Factors in Computing Systems (CHI '17). Association for Computing Machinery, New York, NY, USA, 5158-5170. https: //doi.org/10.1145/3025453.3025873
[67] Woodrow W. Winchester. 2018. Afrofuturism, inclusion, and the design imagination. Interactions 25, 2 (Feb. 2018), 41-45. https://doi.org/10.1145/3182655

[68] Charles Windlin, Anna Ståhl, Pedro Sanches, Vasiliki Tsaknaki, Pavel Karpashevich, Madeline Balaam, and Kristina Höök. 2019. Soma Bits: Mediating technology to orchestrate bodily experiences. In Proceedings of the 4th Biennial Research Through Design Conference. Research Through Design Conference, Delft and Rotterdam, The Netherlands, 16. https://doi.org/10.6084/m9.figshare.7855799.v2

[69] Jill M. Wood. 2020. (In)Visible Bleeding: The Menstrual Concealment Imperative. In The Palgrave Handbook of Critical Menstruation Studies, Chris Bobel, Inga T. Winkler, Breanne Fahs, Katie Ann Hasson, Elizabeth Arveda Kissling, and TomiAnn Roberts (Eds.). Springer, Singapore, 319-336. https://doi.org/10.1007/978981-15-0614-7_25

[70] Sarah Zipp, Tavis Smith, and Simon Darnell. 2019. Development, Gender and Sport: Theorizing a Feminist Practice of the Capabilities Approach in Sport for Development. Fournal of Sport Management 33, 5 (Sept. 2019), 440-449. https://doi.org/10.1123/jsm.2019-0126 Publisher: Human Kinetics Section: Journal of Sport Management. 